\title{
XXIV. On the laws of terrestrial magnetism in different latitudes
}

\section{Biot \& T.S. Evans LL.D.}

To cite this article: M. Biot \& T.S. Evans LL.D. (1817) XXIV. On the laws of terrestrial magnetism in different latitudes, Philosophical Magazine Series 1, 49:226, 95-103, DOI: $10.1080 / 14786441708637851$

To link to this article: http://dx.doi.org/10.1080/14786441708637851

册 Published online: 27 Jul 2009.

Submit your article to this journal $\sqsubset \pi$

Џ Article views: 4

Q View related articles $\asymp$ 
nically Dr. Clanny, and J. H. H. Holmes? Dr. Clanny in his paper on the original safe-lamps, the steam safety-lamps, and the gas-light lamp, states boldly that he was acquainted with the circumstance that explosion would not pass through small tubes; and J. H. H. Holmes, in a libellous advertisement published in the Scoteh and Neweastle papers, accused Sir H. Davy of stealing every thing from Dr. Clanny, except the Doctor's principle of security. I am, sir, respectfully yours, Chelseal, Jan. 25, $181 \dot{7}$.

W. P. KNigur.

XXIV. On the Laus of Terrestrial Magnetism in different Latizudes. By M. Brot; with Notes by T. S. Evans, LL.D. of Christ's Hospital.

[Concluded from p. 16.]

Afren having thus explained all that is at present known, on the dircction of these two magnetic forces in different parts of the earth, it remains for us to consider their absolute intensity. This has been much less attended to than the variation and dip; which, no doubt, arises from its being more difficult to measure with exactness. In this department, I know of no accurate observations except those that $M$. Humboldt has made in his celebrated Voyages and Travels, and those which M. Rössel made in the expedition of Aduiral d'Entrecasteaux*

The

* It has already been mentioned, that the firgt person who noticed the number of ribrations which a needle makes in a stated tiue, was our ingenious countryman, Mr. George Graham, whose experiments are related at full length in the Philosophical Transactions for 1723, No. 389; or, the old Abridgment, rol. vi. part ii. pare 230. Ile began to observe, when the needlc vibrated $10^{\circ}$ on ench side of zero. The following are the times in which 100 vibrations were performed.

\begin{tabular}{|c|c|c|c|c|c|}
\hline & $\begin{array}{l}\text { Vibra- } \\
\text { tions. }\end{array}$ & Jime. & & $\begin{array}{l}\text { Vibra- } \\
\text { tions. }\end{array}$ & Nime. \\
\hline $\begin{array}{r}\text { 17.3. April } 1 \\
2 \\
9 \\
\text { repeated } \\
4 \\
28\end{array}$ & $\begin{array}{l}\{50 \\
\{50 \\
\{50 \\
50 \\
550 \\
50 \\
550 \\
50 \\
500 \\
550 \\
550 \\
50\end{array}$ & $\begin{array}{lr}3^{\prime} & 2^{\prime \prime} \\
2 & 45 \\
3 & 3 \\
2 & 43 \\
2 & 52 \\
2 & 39 \\
2 & 39 \\
2 & 53 \\
2 & 35 \\
2 & 54 \\
2 & 30 \\
2 & 48 \\
2 & 16\end{array}$ & $\begin{array}{r}\text { 1723. May } 20 \\
\text { repented } \\
\text { do. } \\
21 \\
23\end{array}$ & $\left\{\begin{array}{l}50 \\
50 \\
550 \\
250 \\
550 \\
50 \\
50 \\
50 \\
50 \\
50 \\
50 \\
50 \\
50 \\
50\end{array}\right.$ & $\begin{array}{lr}3^{\prime} & 11^{\prime} \\
3 & 1 \\
2 & 38 \\
2 & 23 \\
2 & 38 \\
2 & 20 \\
2 & 41 \\
2 & 28 \\
2 & 40 \\
2 & 27 \\
2 & 41 \\
2 & 30 \\
2 & 11 \\
2 & 28\end{array}$ \\
\hline
\end{tabular}


The researches of $M$. Humboldt on this subjeet bave brought to light a very remarkable phænomenon, which is, the general increase of the intersity in proceeding from the magnetic equator tow'ards the poles.

The same compass which at the departure of M. Humboldt gave 24.5 oscillations, in ten minutes at Paris, gave only 211 at Peru; and it has com tantly varied in the same direction, that is to say, the number of uscillations has always diminished in approaching the magnetic equator, and always increased in receding from it towards the north. These differences cannot be attributed to a diminution of the magnetic strength of the compass; nor can we suppose it would be weakened by the effect of time and heat: for, aiter a residence of three years in the warmest country of the carth, this compass again gave as rapid oscillations at Mexico as at Paris. Lastly, M. Humboldt neglected nothing in his observations to ensure exactness: and they have since been confirmed by the results which he has found in making the needle oscillate successively in the magnetic meridian, and in the plane at right angles to it: for the dip obtained from these data, agrees perfectly with that by experiment, although he did not then know the connexion between these elements which has since been pointed out by $M$. Laplace. The exactnes; of these observations never having been called in question, the truth of the consequences derived from them must also be admitted: and this is the increase of the terrestrial magnetic force, in proceeding from the magnetic equator towards its poles. The experiments made by M. Rössel, at Brest and in New Holland, lead also to the same conclusion.

The explanation just given of our knowledge of the magnetism of the earth, is sufficient to show how very imperfect it is. Ignornut as we are of an immensity of essential data, principally with respect to the variation, we cannot yet expect to arrive at its true causes. We ean therefore only seek for some empiric laws, which, by embracing the greatest possible number of facts, may bring before us their lumeric relations, and point out the principal elements on which to rest the observations.

I have already mestioned, that a great portion of the observed dips; especially in those parts of the globe where the magnetic

The mean of the first 50 vibrations of all the thirteen experiments is $2^{\prime} 49^{\prime \prime}, 4$. The mean of the second 50 is $2^{\prime} 32^{\prime \prime}, 7$ : consequently those that receded farthest from zero required $16, " 7$ of time more than the last, and cach 100 vibrations on an average were made in $y^{\prime} 22^{\prime \prime}, 1$. The difference between these times, shows how necessary it is to begin counting the viluations when the needle reaches some stated number of degrees on each sifle the magnctic wrth: for otherwise no comparison can be made between the number of vibrations in different latitudes. 
equator is circular, might be represented yery exactly, by the action of two magnetic centres placed at a small distance one from the other, near the centre of the earth. Both M. Humboldt and myself have been led to this result in the work which I have mentioned above, and our Memoir was already published when I learned that the celebrated astronomer Mayer had also arrived at the same conchusion, in discussing the dips known in his time: and that he even used it to represent the variations, in a Memoir read to the Suciety of Gottingen, but never printed*. The son of this great astronomer having been so obliging as to send me an extract from it, I have been enahled to convince myself of this identity: and I also found that Mayer had discovered, in an experimental manner, that the law of magnetic attractions is reciprocally as the square of the distance.

This consequence, which we have both deduced from elements so different, appears to indicate something more than a merely empiric law. It is therefore necessary to examine it a little closer. First, it is easy to see that a single magnet placed at the contre of the eartl could not produce all the phrnomena; for then the magnetic equator would be a great circle perpendicular to the right line drawn by the two centres of action, and there would not result from it the inflexion which we have observed in the South Sea. In other respects, such a magnet, in whatever way it might be placed, would necessarily give symmetric phænomena on both sides the plane drawn by its two centres and by the centre of the earth, a symmetry which is no way conformable to the facts observed, especially in the South Sea and the continent of Asia.

Not being able to adopt this simple idea, let us endeavour to depart from it as little as possible; and since we have tound that it represents the observations made in Europe and in the Atlantic Ocean sufficiently well, let us try to make such a modification that it may be scarcely sensible in this part of the globe, and yet that it shall be pretty large in the opposite part, where the magnetic equator suddenly experiences its inflexion. We shall arrive at this by placing a second excentric magnet near this point, whose position and relative energy shall be determined in such a way as to agree with the observations. Now, by making the calculation, we hind it sufficient to give a very small force to

* This circumstance is mentioned by Professor Robison, at the end of the article Magnet ism, in the Supplement to the third edition of the Encyclopedia Britannica. He also gives the results of Mayer's calculations as they were first published by Lichtenburg in his edition of Exliber's Elements of Natural Pbilosophy, 1784. The article bere referred to, and that of Fariation in the body of the work, contain, perhaps, the most complete Theory of Magnetism that has hitherto been published.

Vol.49. No.226. Feb. 1817. 
this magnet, so as to cause the anomalies which occur on this side of the globe to disappear, and also to make the small dips that have been observed to take place in the southern part of the South Sea, agree with the large dips which take place in North America, By thus dividing some other secondary centres in the points of the globe where the irregularities of the variations appear most extraordinary, it is probable that we should end, by representing all of them with exactness, as also the dips and intensities. Thus it is in the system of the world : the principal motion produced by the action of the sun, is modified by the perturbations that are caused by the small masses of the planets. But as it is necessary to know the places of these masses, in order to calculate their influence, so likewise it is necessary that the most accurate observations should point out the position of the different secondary magnetic centres, before we can compute their effects.

Is the central magnetic action, indicated by these phænomena with so much probability, really produced by a magnetic nucleus contained in the interior of the terrestrial globe ; or, is it not the principal resultant of all the magnetic particles disseminated in its substance? Of this we are ignorant: but the last supposition appears to be the most probable. The secondary centres would then be determined by some local attractions becoming preponderant. And, indeed, the observations show in a way not to be doubted, that the general system of dips, of variations, and of magnetic intensities, is very seusibly modified, sometimes in a sudden and irregular manner, by the neighbourhood of great chains of mountains. 'This appears to be confirmed by the singular inflexion which the magnetic equator experiences near the numerons archipelagos of the South Sea. It is well known, indeed, that the islands with which this sea is scattered, are only the summits of very high mountains which elevate themselves quite to a peak from the midst of an ocean where we can find no bottom. If the madrepores, of which they appear to be composed, only form a thin layer, and if, as has been supposed by some very able naturalists, the remainder of their mass has been produced by the action of subterraneous fires, the system of these islands would form the most extensive volcanic chain that there is on the surface of the globe. Then, all the irregularities produced by this system in the general laws of terrestrial magnetism, would have nothing in them but what is simple, and conformable to what is observed in volcanic countries*. For the action of subterraneous fires must necessarily

* If the great magnet of the earth be like many loadstones that are to be met with, and have more than two poles, as the ingenious author supposes, these 
necessarily change the chemical state and the natural arrangement of the ferruginous parts, in places where it exercises itself; which changes cannot be made without affecting the direction of the magnetic needle, and modifying the general action of the globe in those points. There are, indeed, several examples of these alterations which have happened suddenly; and M. Humboldt has observed similar ones at Peru, after a great earthquake*. It is therefore possible, that the particular magnetic centre belonging to the South Sea is owing to similar causes. There exist, without doubt, analogous ones in other countries : and is it not their alterations which during the last two hundred years liave produced these changes of variation of the compass; which changes are so irregular, that it has hitherto been impossible to find any law for them, but which, by this very irregularity, appear to announce that they are not the effect of an uniform and constant cause? According to this ider, nothing in Europe would oblige the compass to return towards the east; and indeed, since it has ceased to decline to the west, it has not been observed to retrograde by any sensible quantity: so that, according to the observations hitherto made, it is impossible to decide whether it will ever retum or not.

The magnetic action of the terrestrial globe is not confined

these will act on each other, and gradually change the forces with which they attract, and thereby infuence the variation of the compass. This action will however, in time, bring the whole to an equilibrium; and as two poles appear to be the nutural and most simple state, to this it will always have a tendency to return, althong the internal changes that take place in the bowels of the earth, arining from cluemical canses, may frequently counteract and retard this operation. The metallic substances which the earth continins near its surface are well known to be continually altering their nature: and if the variation of the compass depend at all upon the changes of these substances, as is commonly supposed, it is evident, these changes take place much more rapidit than is generally believed.

* Father de la Torré observed in Italy, during the great eruption of Mount Vesuvius, that the variation was $16^{\circ}$ in the inorning; at noon it was $14^{*}$; and in the evening it was $10^{\circ}$, and it continued in that state thll the lava grew so cold as no longer to cmit any light in the night, after which it slowly increased to $13 \frac{1}{2}$ degrees, where it remained.

Daniel Bernouili found the needle change its position $45^{\prime}$ by an earthquake.

Professor Muller, at Manheim, observed also that the variation of the needle in that place was greatly affected by the eartbquake in Calabria. Such streams of litva as flowed froin Hecla in the last dreadful eruption, must have made a transference of magnetic matter that woold considerably affect the ncedle: but no observations seem to have been made on the occasion; for we know that common iron-stone, which has no effect on the needle, will, by mere cementation with ariy inflammable substance, become magnetic. In this way Dr. Knight sometimes made artificial loadstones. -Ency. Brit. 
to its interior, or to its surface; it extends also into space, as has been proved by Gay Lussac and myself, in an aërostatie ascent. It evern appears, according to our observations, that the intensity of this action decreases slowly in proportion as we remove from the terrestrial surface; for we did not find any sensible diminution at the height to which we were elevated. Probably its diminution follows the general law of magnetie actions; that is, the inverse ratio of the square of the distance*: if so, it will extend indefinitely into space. Analogy leads us to think that the moon, the sun, and the other celestial bodies, are endowed with similar actions; and the more so, as the composition of aëroliths that have fallen on our globe have shown us that the heavenly bodies contain, in like manner, magnetic substances, such as nickel and iron + . The magnetic actions of all these bodies must, therefore, according to their positions and distances, influence the direction of the magnetic needle on the earth's surface, as well as the absolute intensity of the directing force: and as these positions and distances are continually changing, by the effect of the motion of the earth and of all the planets, it must follow that there will also be perpetual alterations in the magnetic forces. For example: If the magnetic action of the sun and of the moon be sensible, the motion of rotation of the earth round itself, and its motion of revolution round the sun, must produce diurnal and annual 'oseillations in the magnetic needle. Now, not only do such motions exist, but their periods, having been established by a long series of observations, agree with the cause which we have just pointed out. At Paris, according to $M$. Cassini, the maximun of the diurnal variation $\ddagger$ appears to take place between noon and three in the afternoon; then the needle becomes stationary; it then approaches towards the terrestrial meridian, until about eight in the evening; then it stops, and remains stationary during the whole of the night. But in the morning, about eight, it begins again to recede from the meridian. If this second motion re-

move

* This was the law of nagnetic attraction discovered by Coulomb; but Dr. Brook Taylor found by experiments which he made to ascertain it, that at small distances it was nearly in the inverse ratio of the square of the distance: and further off it was inversely as the cube of the distance, or even more than that.-Phil. Transactions, vol, xxix.

$f$ It is here supposed that these stunes come to us from some of the beavenly bodies, which has not yet been proved.

I The diurnal variation was first observed by Mr. George Graham in March, April, and May 1722, and publisbed in the Transactions of the Royal Society, No. 388. The greatest variation westward which he found was $14^{\circ} 45^{\prime}$, and the least $13^{\circ} 50$, by a mean of about 1000 observations. Generally speaking, it was seldom less than $14^{\circ}$, or greater than $14^{\circ} 35^{\circ}$. But the most detailed account of it is given by Mr. Canton, in the Philoso- 
move it further than the evening before, it follows that the vaziation is increasing from one day to the next; if the contrary, it is decreasing. The greatest diurnal variations generally take place during the months of April, May, June, and July; that is to say, between the two equinoxes of spring and autumn. They are at Paris from 13 to 16 minutes. The least are from 8 to 10 minutes, and they take place during the remainder of the year. Now, if we compare the analogous positions of the needle on different days, but at the same hours, in order to have its general progress, we find that, from the spring equinox to the following summer solstice, the variation is decreasing; and that it is increasing all the rest of the year, that is, from the summer solstice to the following spring eyuinox (as is represented in fig. 4). For our knowiedge of these periods we are indebted to M. Cassini, who has established them by observations made during eight years at the Observatory at Paris.

Lastly; numerous observations prove that the magnetic needle is subject to sudden and accidental alterations, which depend on the appearance of those luminous meteors ealled aurorce bo-

plical Transactions, vol. li. p. 899 , from whose observations it appears that, although there be great irregularities in this diurmal change of position of the needie, yet there is a certain average which is kept up with consiHerable steadiness. The following table shows the average of greatest daily change of position in the different months of the year, observed in Mr. Cantors house in Spital Square, London, in 1759.

\begin{tabular}{|c|c|c|c|c|c|}
\hline 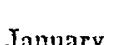 & 111 & May & 11 & Sentember & 1' $4^{\prime \prime}$ \\
\hline February & 858 & June & 1321 & October & 1036 \\
\hline Aarch & 1127 & July & 1314 & November & 89 \\
\hline April & 1226 & August & 1219 & December & 658 \\
\hline
\end{tabular}

Mr. Canton attempts to account for these changes by observing that the force of a magnet is weakened by heat. A small magnet being placed near a compass needle, and E.N.E. from it, so as to make it deflect $45^{\circ}$ from the uatural position, the magnet was covered with a brass vessel, into which hot water was poured. The needle gradually receded from the magnet 3-4ths of a degree, and returned gradually to its place, as the water cooled. The parts of the earth to the eastward are first heated in the morning, and therefore the magnetic force of the carth is weakened, and the needle is made to move to the westward: but as the sun warms the western site of the earth in the afternoon, the needle must move in a contrary direction. Epinus supposes that the suu acts on the earth as a magnet acts on a piece of soft iron; and in the morning propels the fluid into the N.W. parts. The needle directs itself to this constipated fluid, and therefore it points to the eastward of the magnetic north in the afternoon. Neither of these explanations, will account for the great diversity of the diurnal variations in different places, which are so great, that Professor Robison thinks, we can hardly ascribe the diurnal variation to any change in the magnetism of the primitive terrestrial magnet, and must rather look for its cause in local circunstances. 
reales*. The absolute cause of this correspondence between them is unknown, as well as that of the aurora vorealis itself. The influence of this meteor on the needle is commonly of short continuance; for, after being quickly agitated as long as this manifests itself, the needle then returns to its usual position, and proceeds again in the accustomed order of its motions : but it also happens occasionally that it experiences a durable removal from its place, some instances of which have been observed by M. Cassini.

To measure these variations, whether diurnal or annual, Cotlomb used a steel needle, suspended to an assemblage of single filaments of silk as taken from the natural investment of the silkworm, and just sufficient to support it. At the two extremities of the needle he fixed two metal arcs, carrying very fine circular divisions. The whole apparatus was inclosed in a box glazed above, in order that the needle might be observed without being agitated by currents of air. Two micrescopes fixed on the box, and furrished with hair micrometers, could each be directed to the divided arcs carried by the needle, and thus showed its smallest notions. M. de Prony used for the same purpose a long magnetic needle, carrying on its length a telescope which moved with it; the motion of which was observed on a distant mark. M. Humboldt, who made a number of observations with this apparatus, considers it very exaet.

It is important, for the future progress of natural philosophy, that we should determine with accuracy the present intensity of terrestrial magnetism, in the same manner as the weight of the atmosphere and the actual temperature of different climates have been ascertained. By repeating the same observations after some centuries, it would be known whether the magnetic force varies in its energy, at it is certain it has varied in its two directions.

The first method which presents itself to the mind, is to observe the variation, the dip, and the intensity, immediately, by means of three needles appropriated to .this purpose, and then to preserve them carefully for further trials from time to time. As they are liable to lose their magnetism in this interval, they might be restored to the same state by a fresh process, using for this purpose bars well combined together, according to the method of

* "The aurora borealis is observed in Enrope to disturb the needle exceedingly; sometimes drawing it several desces frous its position. It is always found to incrense its deviation from the meridian, and makes the needle point more westerly. This disturbance sometimes amounts to six or seven despes, and is generally observed to be greatest when the aurare borealis is most remarkable. No needle but a magnetic one is affected by the aurora borealis; we may therefore conclude that there is some natural comnexion between this meteor and magnetism."-Robison. 
the double touch*. Indeed, in the application of this process, the needles, by the influence of the extreme bars, are brought instantaneously to a much stronger degree of magnetism than that which they could preserve when they are left to themselves; so that, if their internal constitution remain the same, the de. gree of magnetism in which they are fixed must also remain the same, or at least can only experience that degree of alteration which arises from a change of intensity in the magnetic force of the globe. This method might be rendered much more certain by keeping thus a stated number of well tried needles, the separate effects of which might be ascertained at any previous stated epoch. For if, in trying them again at any other time, it should be found that they have preserved among them their original properties, we might conclude with certainty that they have not been altered in their constitution, and consequently the observation of their absolute energies would determine the real state of the magnetic force.

But the adoption of this method requires the preservation of the needles, and the assurance of their identity. This care might be dispensed with, if we could find a method of fabricating two needles capable of being accurately compared together at any time. For this purpose we must not think of employing steel, which, being a mixture of carbon and iron, is necessarily variable in its proportions. But this defect might be supplied, if we could procure some wire of perfectly pure soft iron by chemical means. For, according to the esperiments of Conlomb, which we have already mentioned, twisting gives such a degree of density and elasticity to iron, that it takes magnetism nearly as well as steel, and retains it equally as long: it is, therefore, only necessary to regulate the quantity of twisting. Now, this is easily done by taking wires of an assigned length and size, and measuring the number of turns which they are twisted by means of a micrometer. Each of these wires should then be magnetized to saturation, and a certain number of them should be collected together, so as to form a bundle, the directing force of which should be measured, either by a magnetic balance or by the method of oscillations. All the difficulty is thus reduced to the procuring of pure iron, and this difficulty belongs solely to chemistry.

If in any given place a piece of soft iron, such as a key for example, be put in the direction of the magnetic dip; the key presently acquires two poles, which act on the magnetic needle in contrary directions. Turn the key about, and its poles will change, and the same effect may be reproduced.

* See Supplement to the $3 \mathrm{~d}$ edition of the Ency. Brit. art. Magnetism, No. 59; and for a list of all the best writers on this subject, see the end of that article, No. 89; or Dr. Thomas Young's very valuable Treatise of Natural Philosophy, vol. ii. page 437. 